\title{
Melnick-Needles syndrome
}

INSERM

\section{Source}

INSERM. (1999). Orphanet: an online rare disease and orphan drug data base. MelnickNeedles syndrome. ORPHA:2484

Melnick-Needles syndrome (MNS) belongs to the otopalatodigital syndrome spectrum disorder and is associated with a short stature, facial dysmorphism, osseous abnormalities involving the majority of the axial and appendicular skeleton resulting in impaired speech and masticatory problems. 